\title{
Comparison of Different Sampling Density Data for Detecting and Measuring Individual-trees in a Mountainous Coniferous Forest using Small-footprint Airborne LiDAR
}

\author{
Tomoaki Takahashi ${ }^{* 1}$, Kazukiyo Yamamoto ${ }^{* 2,3}$ and Yoshimichi Senda ${ }^{* 4}$
}

\begin{abstract}
This study investigated the effects of laser-sampling density on individual-tree detection and tree height estimation changing the sampling density by overlapping three flight data in a mountainous coniferous forest. The LiDAR system used in this study was mounted on a fixed-wing aircraft. The study area was closed-canopy, middleaged Japanese cedar (Cryptomeria japonica) plantation in Japan. We prepared three sets of single flight data $(3.2$ points $\left./ \mathrm{m}^{2}\right)$, three sets of double-overlapping data $\left(6.5\right.$ points $\left./ \mathrm{m}^{2}\right)$ consisted of two single flight data, and one set of triple-overlapping data $\left(9.7\right.$ points $\left./ \mathrm{m}^{2}\right)$ consisted of three single flight data within this study plot. Namely, a total of seven datasets were used in the analysis. The numbers of detected same trees among same laser-sampling density datasets were different and increased with the increase of the density. The detection rate of same trees among all datasets was approximately $55 \%$, and the detected trees belonged to dominant and co-dominant trees within the plot. In all datasets, we found that if a given field tree has relatively lower treetop-elevation and smaller crown radius than that of the nearest field tree, and these trees are close to each other, the lower tree is difficult to detect in mountainous coniferous forest. But the number of detected small trees between $10 \mathrm{~m}$ and $18 \mathrm{~m}$ height increased with the increase of laser-sampling density. LiDAR-derived median and mean tree heights were slightly greater than that of field measured tree height in this study site. Although there were significant differences between field measured and LiDAR-derived tree heights for all datasets $(p<0.01)$, the difference between maximum and minimum RMSE for tree height estimates was only $0.17 \mathrm{~m}$ and the maximum RMSE was $1.02 \mathrm{~m}$. All results of this study indicate that although greater laser-sampling density data can provide information of more varying tree size, 3 or 4 points $/ \mathrm{m}^{2}$ of laser-sampling density data would provide accurate individual-tree detection of upper-storey trees and tree height estimates, given as RMSE, is approximately $1 \mathrm{~m}$ in middle-aged Japanese cedar forests in mountainous areas.
\end{abstract}

Keywords: LiDAR, laser, sampling density, individual-tree, coniferous forest

\section{INTRODUCTION}

Airborne light detection and ranging (LiDAR) is a useful and powerful tool for estimating forest parameters. Especially, many researchers have previously shown that individual-tree height in some coniferous forests with flat and steep slope terrain can be estimated accurately with high-density smallfootprint airborne LiDAR data (HYYPPÄ et al., 2001; PERSSON et al., 2002; TAKAHASHI et al., 2005a). Some researchers have focused on the effects of laser-sampling density on estimation of individual-tree parameters using small-footprint LiDAR for the purpose of reducing costs of data acquisition in recent years (Nilson and Holmgren, 2003; Hirata, 2004; Yu et al.,
Corresponding author: Tomoaki Takahashi

${ }^{* 1}$ Forestry and Forest Products Research Institute,

1, Matsunosato, Tsukuba, Ibaraki, 305-8687, Japan

${ }^{* 2}$ Graduate School of Bioagricultural Sciences,

Nagoya University, Furo-cho, Chikusa, Nagoya,

Aichi, 464-8601, Japan

\footnotetext{
*3 Japan Science and Technology Agency/CREST, Kawaguchi 332-0012, Japan

${ }^{* 4}$ Nakanihon Air Service Co., Ltd., 2, Tonogama, Ho-jo-aza, Toyoyamatyo-oaza, Nishikasugai, Aichi, 480-0202, Japan
} 
2004). In general, when the sampling density decreases, not only the number of detected trees would decrease (ZIMBLE $e t$ $a l ., 2003)$, but also the accuracy of tree height estimates would deteriorate because of missing treetops (GAVEaU and HILl, 2003). Tree height estimates with small-footprint airborne LiDAR data would be principally calculated by subtracting digital terrain model (DTM) from digital surface model (DSM). Therefore it is considered that not only the accuracy of the DSM, but also the accuracy of the DTM would significantly affect individual-tree height estimates.

Although Kraus and PfEIFER, (1998) indicated that the steeper the slope angle become and the lower the number of laser pulses that hit the ground surface become, the accuracy of DTM would be lower. Our previous study showed that the root mean square error (RMSE) of the LiDAR-derived tree height estimates was less than $1 \mathrm{~m}$ in a mountainous coniferous forest with steep slope in Japan when using a helicopter-borne scanning LiDAR which produced highdensity data (e.g., more than 8 to 10 points $/ \mathrm{m}^{2}$ ) by single flight (TAKAHASHI et al., 2005a). In order to acquire high-density laser data, researchers may select two ways, one is application of helicopter-borne scanning LiDAR systems with lower flight speed and altitude by single flight, and the other is application of LiDAR systems mounted on fixed-wing aircrafts with higher flight speed and altitude by several repeat flights. While these ways have both merits and demerits in terms of cost, quality of the acquired data, and measurement time, the former way seem to be able to provide higher quality data and the latter way seem to be more suitable for the measurement for wide area in terms of cost, respectively. Although we found that the helicopter-borne LiDAR could provide good estimates of individual-tree heights in a mountainous coniferous forest in Japan, the relationship between the laser-sampling density and the accuracy of LiDAR-derived tree height estimates when using fixed-wing airborne LiDAR remains unknown.

For the purpose of reducing costs of LiDAR data acquisition maintaining a preferable accuracy of the estimates of forest parameters in mountainous forests with steep slopes, we should investigate the effects of laser-sampling density on the estimation of individual-tree parameters in such forests. Therefore in this study, we investigated the effects of lasersampling density on individual-tree detection and tree height estimation changing the density by overlapping three flight data acquired by a fixed-wing airborne LiDAR in a mountainous coniferous forest in Japan.

\section{MATERIALS AND METHODS}

Ground Reference Data

The study area was the Nagoya University experimental forest located in Aichi Prefecture in central Japan (lat. $35^{\circ} 12$ ' $\mathrm{N}$, long. $137^{\circ} 33^{\prime}$ E, 930m asl). Even-aged (49-year-old) closedcanopy coniferous plantation was chosen for this study. We established a square plot (approximately $50 \times 50 \mathrm{~m}$ ) in the plantation, and the terrain slope within the plot ranged from 11.4 to 47.8 degrees. The plot mainly consisted of planted Japanese cedar (Cryptomeria japonica) (235 trees); however, planted hinoki cypress (Chamaecyparis obtusa) (21 trees), Japanese red pine (Pinus densiflora) (2 trees), fir (Abies homolepis) (2 trees), and sawara cypress (Chamaecyparis pisifera) (2 trees) were also mixed in. The forest floor was covered with litter, and the understorey vegetation that had not been weeded mainly consisted of kumazasa (Sasa veitchii) and shiromoji (Lindera triloba) with a height less than approximately $2 \mathrm{~m}$. Because there were two trees whose crown shape was distorted, a total of 260 trees were used for the analysis in this study.

During fall and winter of 2003 , i.e., after the growth season had ended, tree measurements were completed. Static GPS surveys were used to determine the accurate position of a reference point in an open area near the plot; subsequently, the tree positions were surveyed in relation to the reference point as follows. The positions of the center of all tree stems were measured using a compass with an accuracy of $1^{\circ}$ and a portable laser distance measurement with an accuracy of $1 \mathrm{~mm}$ (DISTO4, Leica Geosystems, Heerbrugg, Switzerland), thus making corrections for each stem diameter at the height at which the laser beam was incident. Then, tree heights and diameters at breast heights (1.3m above ground level) of all individual-trees were measured using a dendrometer with an accuracy of $1 \mathrm{~cm}$ (Ledha-Geo, Jenoptik laser, Jena, Germany) and a diameter tape, respectively. Subsequently, the projected on-ground crown radii at a height of $1.3 \mathrm{~m}$ above ground level (eight directions) were measured using a measuring tape.

Although it was only one year, there was a gap between the acquisition time of the LiDAR data (fall 2004) and the ground truth data (fall and winter 2003). Because we mainly address individual-tree height estimation by LiDAR, field measured tree height values in 2003 should be corrected in some degree. To ascertain the one-year increment in tree height, we used the results of stem analysis for three sampled trees (Japanese cedar) that had been used for estimating past tree heights as of 2001 in our previous study (TAKAHASHI $e$ t al., 2005a). Richards growth function (RICHARDS, 1958) was used to predict the height as of $2004(\mathrm{H}(t))$ for each sampled tree as follows:

$$
H(t)=M\left(1-e^{a t}\right)^{b}
$$

where $M, a$, and $b$ are parameters and $t$ is age. These three parameters were estimated with the results of the stem analysis for each sampled tree. The predicted height increments between 2003 and 2004 for each sampled tree are shown in Table 1 . In this study, the arithmetic mean value of the height increments was added to field measured tree height values as of 2003 for each standing tree within the plot. Subsequently, the corrected tree heights and uncorrected 
Table 1 Predicted parameters $(M, a$, and $b)$ of Richards growth function for three sampled trees and tree height increments between 2003 and 2004

\begin{tabular}{lrrrr}
\hline & Stem 1 & Stem 2 & Stem 3 & Mean \\
\hline $\mathrm{M}$ & 28.485 & 36.923 & 22.041 & \\
$\mathrm{a}$ & -0.047 & -0.020 & -0.050 & \\
$\mathrm{~b}$ & 1.654 & 1.046 & 1.365 & \\
Increment & 1.009 & 1.013 & 1.007 & 1.010 \\
\hline
\end{tabular}

Richards growth function is shown in Eq.(1) in the text.

Table 2 Summary of plot reference data

\begin{tabular}{|c|c|c|}
\hline & Range & Mean $\pm \mathrm{SD}^{c}$ \\
\hline Diameter at breast height $(\mathrm{cm})^{\mathbf{a}}$ & $8.2-49.0$ & $25.7 \pm 7.7$ \\
\hline Tree height $(\mathrm{m})^{\mathbf{b}}$ & $9.0-29.8$ & $19.3 \pm 3.5$ \\
\hline Crown radius $(\mathrm{m})^{\mathbf{a}}$ & $0.4-3.4$ & $1.6 \pm 0.5$ \\
\hline
\end{tabular}

${ }^{\mathrm{a}}$ Measured data as of 2003

${ }^{\mathrm{b}}$ Predicted data as of 2004

'SD denotes standard deviation

DBH and crown radius were used as reference data in the analysis. A summary of the plot reference data is shown in Table 2. Hereafter, trees identified in the field are called "field tree" in this study.

\section{LiDAR Data Collection}

The LiDAR data acquisition was performed on 4th November 2004 using a fixed-wing airborne laser scanner (Optech ALTM 2050) operated by Nakanihon Air Service Co., Ltd., Japan. In this study, the position of the reflecting object was determined from the first and last pulse. Laser measurements were made on three parallel flight lines, hereafter, referred to as $S_{1}, S_{2}$, and $S_{3}$. The settings of the LiDAR system for each flight were almost same. The beam divergence was $0.19 \mathrm{mrad}$, giving a footprint diameter of approximately $0.2 \mathrm{~m}$ with the flight altitude of approximately $1,080 \mathrm{~m}$ above ground level, and the aircraft's speed was approximately $70 \mathrm{~m} / \mathrm{s}$. The scan mirror frequency, laser pulse frequency, and the scan width were $70 \mathrm{~Hz}, 50,000 \mathrm{~Hz}$, and \pm $4.9^{\circ}$, respectively. By these specifications, the theoretical average distance between footprints was approximately $0.5 \mathrm{~m}$ along the scan line and approximately $1.0 \mathrm{~m}$ along the flight line for each flight. We firstly prepared three sets of single flight data, i.e., $S_{1}, S_{2}$, and $S_{3}$, then three sets of doubleoverlapping data $\left(D_{12}, D_{13}\right.$, and $\left.D_{23}\right)$ consisted of $S_{1}$ and $S_{2}, S_{1}$ and $S_{3}$, and $S_{2}$ and $S_{3}$, respectively. Finally, one set of tripleoverlapping data $\left(\mathrm{T}_{123}\right)$ consisted of all three single flight data was prepared. So a total of seven datasets were used in this analysis. The details of incident angle of laser pulses and actual laser-sampling density for each single flight data within the plot are shown in Table 3 .

Processing LiDAR Data, Detecting Individual-tree Crowns and Estimating Tree Heights

Parameter settings in processing data were not changed for all datasets. The methods for preprocessing each dataset and creating a digital surface model (DSM), digital terrain model (DTM), and canopy height model (CHM) within the plot were the same as reported in TAKAHASHI et al. (2005a). Firstly, the unevenly distributed laser reflection point data was converted into two raster layers with a pixel size of $0.5 \mathrm{~m}$ because theoretical laser-sampling density was approximately 3.2 points $/ \mathrm{m}^{2}$ for single flight data. The first raster layer, referred to as $\mathrm{DSM}_{\text {raw, }}$ was assigned the height value of the highest laser reflection point within each pixel using only first pulse data. The second raster layer, referred to as DTM raw, was assigned the lowest laser reflection point within each pixel using both first and last pulse data. Then both DSM $_{\text {raw }}$ and DTM $_{\text {raw }}$ were refined by removing noise and interpolated for null-pixels. The interpolation methods used in this study were spline interpolation for DTM (MAGNUSSEN and BOUDEWYN, 1998; RIAÑo et al., 2003), and inverse distance weighting method that does not change the original value for DSM (Popescu et al., 2002). Subsequently, CHM was computed by subtracting DTM from DSM.

Individual-tree crowns were identified using our software named LiDAS (LiDAR Data Analysis System), which has functions to identify individual canopy gaps and segment tree crowns (TAKAHASHI et al., 2005b). Similar algorithms of segmenting tree crowns based on both the extraction of local maxima (WULDER et al., 2000) and region growing were shown in HYYPPÄ et al. (2001) and MALTAMO et al. (2003). In order to locate trees, local maxima which are considered to be treetops were searched by $3 \times 3$ moving window in low-pass filtered (i.e., smoothed) DSM, and then used for region growing segmentation. This system requires the determination of an important threshold value, which is the difference between the height of the crown base within the smoothed DSM and the ground surface height of canopy gaps within the smoothed DSM. The best threshold value was determined by trial and error, and $8 \mathrm{~m}$ was selected as the threshold value in this study. After generating individual-tree crown outlines by LiDAS for the smoothed DSM, they were laid over CHM. LiDAR-derived individual-tree heights were computed as the maximum value of CHM within each segmented crown (MALTAMo et al., 2004).

Evaluation Method for Detected Tree Crowns and Estimates of Tree Heights

As mentioned before, LiDAR-derived tree heights were directly derived from $\mathrm{CHM}$ which was calculated by subtracting DTM from DSM in this study. Therefore, before evaluating both detection of individual-tree crowns and 
measurement of tree heights, the statistics of DSM and DTM were investigated for each dataset. Also, we incidentally investigated the relationships between two single flight datasets among three flight lines $\left(S_{1}, S_{2}\right.$, and $\left.S_{3}\right)$ concerning the elevation of DSM and DTM to assess reproducibility of DSM and DTM derived from different single flight lines.

Each LiDAR-detected tree crown had to be identified at the location of field tree for all datasets. If one field tree existed within a segmented crown, the detection was considered to be correct. If several field trees existed within a segmented crown, the field tree with the highest treetop-elevation was identified as the segmented crown, and the remaining unidentified field trees were defined as undetected trees. For calculating individual-treetop-elevation, we used field tree heights and ground elevations surveyed in the field. The tree matching process is based on the fact that dominant and codominant trees are more likely to detect than intermediate or suppressed trees in Japanese cedar plantations in a mountainous forest by LiDAR measurements as shown in our previous study (TAKAHASHI et al., 2005). In order to ensure the accuracy of the tree matching process, we assessed the differences between horizontal location of field tree with the highest treetop-elevation and local maximum pixel within individual crown segment. In this assessment, the detected same trees among all datasets were targeted. Then, to investigate the characteristics of detected and undetected trees, we mainly focused on mean crown radius and tangent $(\tan \theta)$ consisted of horizontal distance and viewing angle (depression or elevation angle) from a given field treetop to the closest field treetop (see Fig. 1) referencing a method in PERSSON et al., (2002). In this study, we denoted that the depression and elevation angle have negative and positive value, respectively.

For the evaluation of tree height estimates, the detected

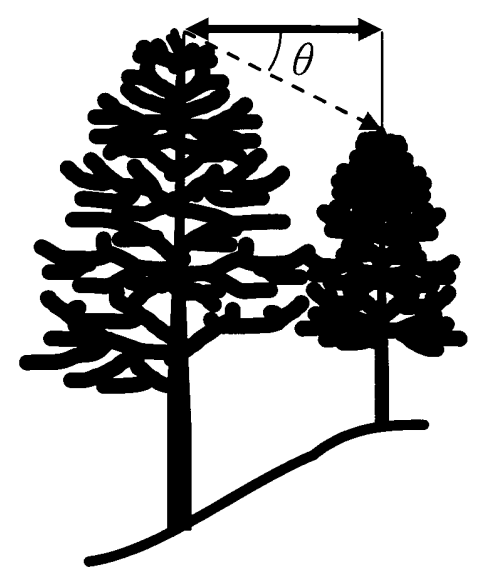

Fig. 1 Horizontal distance (solid arrow) and viewing angle $(\theta)$ from a given field treetop (left tree) to the closest field treetop (right tree)

In the case of this figure, $\theta$ represents depression angle. same trees among seven datasets were mainly targeted. We firstly assessed the statistical significant difference of average such as mean and median tree heights among groups, including filed data and seven datasets. In this study, Friedman test (Hollander and Wolfe, 1973) and the Scheffe procedure as a post hoc test were applied in the statistical tests. Next, RMSE for LiDAR-derived tree height estimates was computed for each dataset as follows:

$$
\operatorname{RMSE}=\sqrt{\frac{\sum_{i=1}^{n}\left(h_{1(i)}-h_{\text {rii }}\right)^{2}}{n}}
$$

where $h_{\mathrm{L}}$ and $h_{\mathrm{f}}$ are LiDAR-derived and field measured tree height, respectively. Finally, we investigated the relationships between LiDAR-derived and field measured tree heights by regression analysis, in which models were fitted to the data using the least-squares method. Only for the regression analysis, the detected same trees among same laser-sampling density datasets were targeted.

\section{RESULTS}

The statistics of DSM and DTM for each dataset are shown in Table 3. Five statistics, i.e., minimum, maximum, mean, standard deviation, and coefficient of variation of the elevation were almost same among all datasets for DSM and DTM. Table 4 shows that the differences between two single flight datasets among three flight lines $\left(S_{1}, S_{2}\right.$, and $\left.S_{3}\right)$ concerning the elevation of DSM and DTM. Although mean errors of DSMs and DTMs were almost zero, RMSEs of DSMs were grater than that of DTMs. Fig. 2 shows that the example of scatter plots for the relationship between two single flight datasets $\left(S_{1}\right.$ and $\left.S_{2}\right)$ concerning the elevation of DSM and DTM. Many outliers exist in the relationship between two DSMs, on the contrary, there are few outliers in the relationship between two DTMs.

The differences between locations of field tree and local maximum within each crown segment for detected same trees among all datasets are shown in Table 5 . In this table, $\mathrm{dx}$ and dy denote the mean differences for easting and northing, respectively, and they were computed by subtracting the position coordinate of local maxima from that of the corresponding field tree for each direction. They had negative values and their magnitude of the values was small for all datasets. RMSEs for the differences were slightly grater than the resolution of raster data used in this study for all datasets except $\mathrm{S}_{2}$.

The number of detected trees for each dataset is shown in Table 6. The detection rates were almost same among all datasets. But the numbers of detected same trees among same laser-sampling density datasets were different and increased with the increase of the density. The detection rate of same trees among all datasets was approximately $55 \%$. Both Table 7 and Fig. 3 show the characteristics of detected and undetected same trees among all datasets. Also, trees which were either 
Table 3 Actual laser-sampling density and incident angle within plot, and statistics of DSM and DTM for each dataset

\begin{tabular}{|c|c|c|c|c|c|c|c|c|}
\hline & & $\mathrm{S}_{1}{ }^{\mathrm{a}}$ & $\mathrm{S}_{2}{ }^{\mathrm{a}}$ & $\mathrm{S}_{3}{ }^{\mathbf{a}}$ & $D_{12}{ }^{b}$ & $\mathrm{D}_{13}{ }^{b}$ & $\mathrm{D}_{23}{ }^{\mathbf{b}}$ & $T_{123}{ }^{c}$ \\
\hline \multirow{2}{*}{\multicolumn{2}{|c|}{$\begin{array}{l}\text { Sampling density (points } / \mathrm{m}^{2} \text { ) } \\
\text { Incident angle (degree) }\end{array}$}} & 3.3 & 3.3 & 3.1 & 6.6 & 6.4 & 6.4 & 9.7 \\
\hline & & $0.5-3.7$ & $0.0-2.2$ & $0.0-3.3$ & & & & \\
\hline \multirow{5}{*}{ DSM } & Min & 938.50 & 938.46 & 938.52 & 938.46 & 938.50 & 938.52 & 938.52 \\
\hline & Max & 997.98 & 997.97 & 997.54 & 997.98 & 997.98 & 997.97 & 997.98 \\
\hline & Mean & 967.58 & 967.62 & 967.63 & 967.79 & 967.76 & 967.81 & 967.95 \\
\hline & $\mathrm{SD}^{\mathbf{d}}$ & 14.05 & 14.05 & 14.04 & 14.09 & 14.08 & 14.08 & 14.08 \\
\hline & $\mathrm{CV}(\%)^{\mathbf{e}}$ & 1.45 & 1.45 & 1.45 & 1.46 & 1.45 & 1.46 & 1.46 \\
\hline \multirow{5}{*}{ DTM } & Min & 938.56 & 938.65 & 938.52 & 938.54 & 938.57 & 938.60 & 938.53 \\
\hline & Max & 978.80 & 978.73 & 979.24 & 978.67 & 979.10 & 979.06 & 979.07 \\
\hline & Mean & 952.89 & 952.87 & 952.89 & 952.84 & 952.86 & 952.85 & 952.82 \\
\hline & $\mathrm{SD}^{\mathrm{d}}$ & 9.57 & 9.58 & 9.62 & 9.59 & 9.60 & 9.59 & 9.59 \\
\hline & $C V(\%)^{\mathbf{e}}$ & 1.00 & 1.01 & 1.01 & 1.01 & 1.01 & 1.01 & 1.01 \\
\hline
\end{tabular}

${ }^{a}$ Three sets of single flight data, i.e., $S_{1}, S_{2}$, and $S_{3}$

${ }^{b}$ Three sets of double-overlapping data $\left(D_{12}, D_{13}\right.$, and $\left.D_{23}\right)$ consisted of $S_{1}$ and $S_{2}, S_{1}$ and $S_{3}$, and $S_{2}$ and $S_{3}$, respectively

' One set of triple-overlapping data $\left(T_{123}\right)$ consisted of all three single flight data

${ }^{\mathrm{d}} \mathrm{SD}$ denotes standard deviation

${ }^{\mathrm{e}} \mathrm{CV}$ denotes coefficient of variation

Table 4 Differences between two single flight data concerning DSM and DTM

\begin{tabular}{lccccccc}
\hline & \multicolumn{3}{c}{ DSM } & & \multicolumn{3}{c}{ DTM } \\
\cline { 2 - 4 } \cline { 6 - 8 } & $\mathrm{S}_{1}{ }^{\mathbf{a}}-\mathrm{S}_{2}{ }^{\mathbf{a}}$ & $\mathrm{S}_{\mathbf{1}}{ }^{\mathbf{a}}-\mathrm{S}_{\mathbf{3}}{ }^{\mathbf{a}}$ & $\mathrm{S}_{2}{ }^{\mathbf{a}}-\mathrm{S}_{\mathbf{3}}{ }^{\mathbf{a}}$ & & $\mathrm{S}_{1}{ }^{\mathbf{a}}-\mathrm{S}_{2}{ }^{\mathbf{a}}$ & $\mathrm{S}_{1}{ }^{\mathbf{a}}-\mathrm{S}_{3}{ }^{\mathbf{a}}$ & $\mathrm{S}_{2}{ }^{\mathbf{a}}-\mathrm{S}_{3}{ }^{\mathbf{a}}$ \\
Mean error (m) & -0.04 & -0.05 & -0.02 & & 0.01 & -0.01 & -0.02 \\
RMSE (m) & 1.64 & 1.63 & 1.67 & & 0.24 & 0.28 & 0.22 \\
\hline
\end{tabular}

${ }^{a}$ Three sets of single flight data, i.e., $\mathrm{S}_{1}, \mathrm{~S}_{2}$, and $\mathrm{S}_{3}$
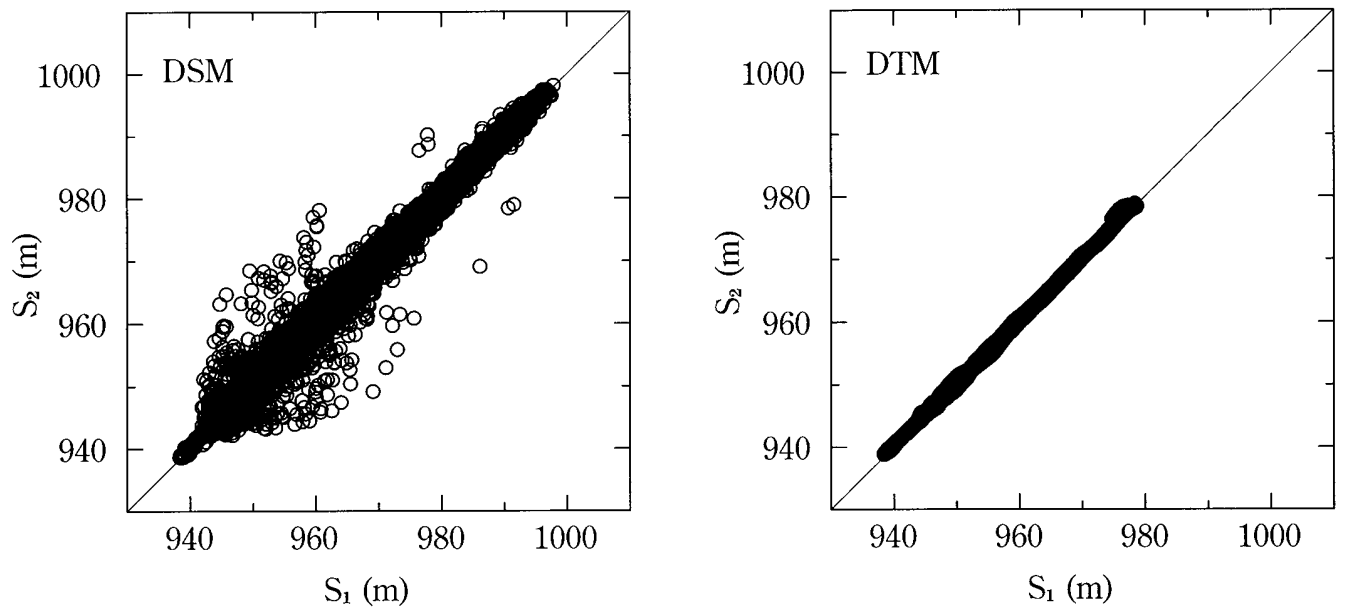

Fig. 2 The relationship between two single flight data $\left(\mathrm{S}_{1}\right.$ and $\left.\mathrm{S}_{2}\right)$ concerning the elevation of DSM (left) and DTM (right)

The line in each graph indicates $1: 1$ correspondence. The number of data in each graph coincides with the number of pixels within study area. 


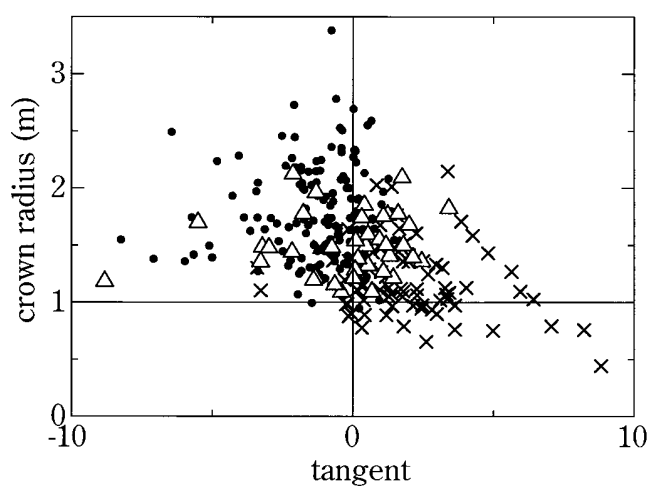

Fig. 3 Characteristics of detected and undetected trees for the same trees among all datasets, and trees which were either detected or undetected among different datasets

We denoted such trees as "ambivalently detected trees". This figure shows the relationship between mean crown radius and tangent $(\tan \theta)$ consisted of horizontal distance and viewing angle (depression or elevation angle) from a given field treetop to the closest field treetop (see Fig. 1). Black dots, crosses, and white triangles denote detected, undetected, and ambivalently detected trees, respectively. detected or undetected among different datasets were shown in Table 7 and Fig. 3, and we denoted such trees as "ambivalently detected trees". We can see most of the detected trees have depression angles and their crown radii are larger than that of undetected trees. On the contrary, most of the undetected trees have elevation angles. Moreover, many ambivalently detected trees exist around the border between detected and undetected trees, although some of them exist beyond the border in Fig. 3 .

Table 8 shows the results of the statistical significant difference for the average of tree heights among groups, including filed data and seven datasets. There were significant differences between $h_{\mathrm{f}}$ and $h_{\mathrm{L}}$ for all datasets $(\phi<0.01)$. But there were not significant differences among same lasersampling density datasets $(p>0.05)$. Moreover, some pairs among different laser-sampling density datasets had significant difference. In Table 7, we can see LiDAR-derived median and mean tree height and RMSE for the estimates increase slightly with the increase of laser-sampling density, but the differences are small. Then, there was a strong liner relationship between $h_{\mathrm{L}}$ and $h_{\mathrm{f}}$ for all datasets as shown in Fig. 4. As seen in this figure, there is no outlier in the

Table 5 Differences between locations of field tree and local maximum within each crown segment for detected same trees among all datasets

\begin{tabular}{lccccccc}
\hline & $\mathrm{S}_{\mathbf{1}}{ }^{\mathbf{a}}$ & $\mathrm{S}_{\mathbf{2}}{ }^{\mathbf{a}}$ & $\mathrm{S}_{\mathbf{3}}{ }^{\mathbf{a}}$ & $\mathrm{D}_{\mathbf{1 2}}{ }^{\mathbf{b}}$ & $\mathrm{D}_{\mathbf{1 3}}{ }^{\mathbf{b}}$ & $\mathrm{D}_{\mathbf{2 3}}{ }^{\mathbf{b}}$ & $\mathrm{T}_{\mathbf{1 2 3}}{ }^{\mathbf{c}}$ \\
\hline$d x^{\mathbf{d}}$ & -0.30 & -0.22 & -0.25 & -0.24 & -0.26 & -0.25 & -0.25 \\
$d y^{\mathbf{d}}$ & -0.12 & -0.02 & -0.14 & -0.09 & -0.14 & -0.09 & -0.12 \\
$\mathrm{RMSE}^{\mathbf{e}}$ & 0.58 & 0.47 & 0.53 & 0.53 & 0.54 & 0.51 & 0.52 \\
\hline
\end{tabular}

${ }^{a}$ Three sets of single flight data, i.e., $\mathrm{S}_{1}, \mathrm{~S}_{2}$, and $\mathrm{S}_{3}$

${ }^{\mathbf{b}}$ Three sets of double-overlapping data $\left(\mathrm{D}_{12}, \mathrm{D}_{13}\right.$, and $\left.\mathrm{D}_{23}\right)$ consisted of $\mathrm{S}_{1}$ and $\mathrm{S}_{2}, \mathrm{~S}_{1}$ and $\mathrm{S}_{3}$, and $\mathrm{S}_{2}$ and $\mathrm{S}_{3}$, respectively.

${ }^{c}$ One set of triple-overlapping data $\left(\mathrm{T}_{123}\right)$ consisted of all three single flight data.

${ }^{\mathrm{d}} d x$ and $d y$ denote the differences for easting and northing, respectively.

${ }^{e}$ RMSE means two-dimensional distance between the corresponding trees.
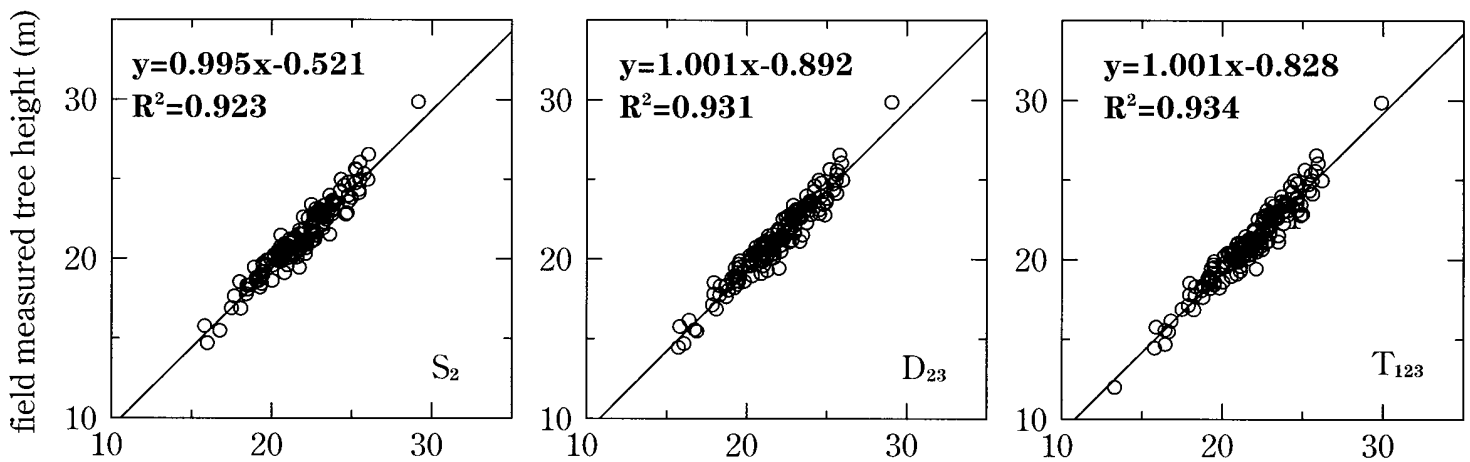

LiDAR-derived tree height (m)

Fig. 4 The relationship between LiDAR-derived and field measured tree heights for one single flight data $\left(\mathrm{S}_{2}\right)$, one double-overlapping data $\left(\mathrm{D}_{23}\right)$, and one triple-overlapping data $\left(\mathrm{T}_{123}\right)$ $\mathrm{S}_{2}, \mathrm{D}_{23}, \mathrm{~T}_{123}$ are described in the text. 
relationship between $h_{\mathrm{L}}$ and $h_{\mathrm{f}}$ for all datasets.

\section{DISCUSSION AND CONCLUSION}

Although there were seemingly no differences among all datasets for DSM and DTM judging from Table 3 and 4, spatial localization of each pixel within DSM and DTM was not actually considered in the statistics. In fact, Fig. 2 shows many outliers exist in the relationship between two DSMs. Most of the pixels of the outliers are considered to be edge pixels of individual-tree crowns. Because the location of each laser measurement point by one flight does not always correspond to that of another flight, there is no telling that either the measurement point data around crown edges will belong to crown pixels or ground pixels (i.e., gap pixels) for each flight data. Moreover, the effects of both displacement and selection of point data within each pixel around crown edges would not be ignored during conversion point data into raster data, especially when the laser sampling density is low. On the other hand, there are few outliers in the relationship between two DTMs in Fig. 2 and both mean errors and RMSEs for the differences between two DTMs were smaller than that of DSMs as shown in Table 4. The cause was considered to be much less variation between adjacent pixels within DTM than that of DSM, and indeed field ground surface generally have much less variation than canopy surface above the ground. But we should know that the number of null-pixels which had been interpolated within DTM was much more frequent than that of DSM in closed-canopy Japanese cedar forests (TAKAHASHI et al., 2006), and the effects of the interpolation would also cause such less variation between adjacent pixels within DTM.

As reported by ZimBLE et al., (2003), local maxima within DSM or CHM do not always correspond to treetops, especially when the laser sampling density is low. Therefore, we applied the tree matching approach based on crown segment because this approach was considered to be less mismatching than an approach which is based on using only local maxima. Table 5 shows the accuracy of the tree matching process used in this study. The results in this table indicate that the tree matching was considered as reasonable and proper. Moreover, we found an interesting tendency that both $d x$ and $d y$ had negative values for all datasets, thus indicating that LiDAR-detected local maxima were off to southwest from locations of stems. This is because even coniferous tree stems are not always upright on steep slops and the treetops are likely to tilt toward the valley side (HEURICH et al., 2003; TAKAHASHI et al., 2005a). In fact, the study area was southwestern slope as shown in our previous study (TAKAHASH et al., 2005a). The effects of this tendency on tree height estimation will be discussed later on.

Although the detection rates of tree were not so different among all datasets, the variation of the number of detected trees among double-overlapping datasets was smaller than that of single flight datasets as shown in Table 6. This indicates that if the laser-sampling density increase, the stability to detect trees would rise. Also, the number of detected same trees among same laser-sampling density datasets increased with the increase of the density, thus indicating that the probability to detect same trees would rise by the grater laser-sampling density. Therefore, greater laser-sampling density would be

Table 6 Detection rates of trees, tree height estimates, and root mean square errors (RMSEs) between field measured and LiDAR-derived tree heights

\begin{tabular}{|c|c|c|c|c|c|c|c|c|}
\hline & \multicolumn{3}{|c|}{ Single flight ${ }^{\mathrm{a}}$} & \multicolumn{3}{|c|}{ Double-overlapping ${ }^{b}$} & \multicolumn{2}{|c|}{ Triple-overlapping $^{\mathbf{c}}$} \\
\hline & $\mathrm{S}_{1}$ & $\mathrm{~S}_{2}$ & $\mathrm{~S}_{3}$ & $\overline{D_{12}}$ & $\mathrm{D}_{13}$ & $\mathrm{D}_{23}$ & $T_{123}$ & Field data ${ }^{d}$ \\
\hline Number of detected trees for each dataset & 160 & 168 & 163 & 163 & 162 & 164 & 160 & \\
\hline Detection rates of trees for each dataset $(\%)$ & 62 & 65 & 63 & 63 & 62 & 63 & 62 & \\
\hline $\begin{array}{l}\text { Number of detected same trees among same laser-sampling density } \\
\text { datasets }\end{array}$ & 145 & 145 & 145 & 154 & 154 & 154 & 160 & \\
\hline $\begin{array}{l}\text { Detection rates of same trees among same laser-sampling density } \\
\text { datasets (\%) }\end{array}$ & 56 & 56 & 56 & 59 & 59 & 59 & 62 & \\
\hline Number of detected same trees among all datasets & 142 & 142 & 142 & 142 & 142 & 142 & 142 & \\
\hline Detection rates of same trees among all datasets (\%) & 55 & 55 & 55 & 55 & 55 & 55 & 55 & \\
\hline Median tree heights for detected same trees among all datasets (m) & 22.0 & 22.0 & 22.0 & 22.2 & 22.2 & 22.1 & 22.2 & 21.1 \\
\hline Mean tree heights detected same trees among all datasets (m) & 21.9 & 22.0 & 22.0 & 22.1 & 22.1 & 22.1 & 22.2 & 21.4 \\
\hline $\begin{array}{l}\text { e RMSE of tree height estimates for detected same trees among all } \\
\text { datasets }(\mathrm{m})\end{array}$ & 0.85 & 0.90 & 0.90 & 0.97 & 0.95 & 0.96 & 1.02 & \\
\hline
\end{tabular}

a Three sets of single flight data, i.e., $\mathrm{S}_{1}, \mathrm{~S}_{2}$, and $\mathrm{S}_{3}$

${ }^{\mathbf{b}}$ Three sets of double-overlapping data $\left(D_{12}, D_{13}\right.$, and $\left.D_{23}\right)$ consisted of $S_{1}$ and $S_{2}, S_{1}$ and $S_{3}$, and $S_{2}$ and $S_{3}$, respectively.

${ }^{\mathrm{c}}$ One set of triple-overlapping data $\left(\mathrm{T}_{123}\right)$ consisted of all three single flight data.

d The numbers of field tree were 260 within the plot.

${ }^{\text {e }}$ RMSEs were computed using Eq. 2 in the text. 
better for both the stability and reproducibility of detecting individual-tree crowns. However, we should note that the relationships between laser incident angle (Table 3) and the detection rate of trees for single flight datasets (Table 6). The acuter the incident angle became, the greater the detection rates became in this study site, although the magnitude of incident angle was fairly small for flight data. HOLMGREN et al., (2003) simulated the effects of laser scanning angle on tree height estimation, and they showed that laser height percentiles and proportion of canopy returns changed with by increasing scanning angle within $20 \mathrm{~m} \times 50 \mathrm{~m}$ simulated forest plots. Similar simulations and results were found in LoveLL $e t$ al., (2005). Considering these reports, detection rates of trees whose treetop-elevation is low would be decreased with the increase of scanning angle. Therefore, not only the effect of laser-sampling density, but also the effect of flight direction of LiDAR systems, laser incident angle, terrain slope angle, and slope aspect on the detection of individual-tree crowns would be crucial in mountainous forests. These effects should be investigated in detail in the future.

As shown in Table 7 , the detection rate of same trees among all datasets was $54.6 \%$, and rates of ambivalently detected trees and undetected trees were $14.6 \%$ and $30.8 \%$, respectively. Both Table 7 and Fig. 3 indicate that if a given field tree has relatively lower treetop-elevation and smaller crown radius than that of the nearest field tree, and these trees are close to each other, the lower tree is difficult to detect in mountainous coniferous forests. Similar tendency for the detection of individual-trees seems to be found in boreal coniferous forests with flat terrain (PERSSON et al., 2002). Conversely, it is indicated that most of the dominant and codominant trees would detect accurately in middle-aged Japanese cedar plantations in mountainous forests by the lasersampling density of 3 or 4 points $/ \mathrm{m}^{2}$ as shown in Fig. 3. Many ambivalently detected trees existed around the border between detected and undetected trees in Fig.3, but some of them whose tangent were small existed beyond the border. Although it is not known the exact reason, such trees might be surrounded another neighbor trees with higher treetopelevation. Moreover, we should note that trees whose crown radius with smaller than $1 \mathrm{~m}$ can hardly detect. This is considered to be essentially the limitation of detection by $3 \times 3$ local maximum filtering for DSM whose resolution was $0.5 \mathrm{~m}$.

LiDAR-derived median and mean tree heights for the detected same trees were slightly greater than that of field measured tree heights in this study site (Table 6). As shown in Table 8 , there were significant differences between $h_{\mathrm{r}}$ and $h_{\mathbf{L}}$ for all datasets $(\phi<0.01)$. One of the reasons for the differences might be insufficient correction for field individualtree heights measured in 2003. However, it would be difficult to determine each tree height growth of all standing trees within the plot exactly because even the sampled trees had variations in height growth as shown in Table 1 . Instead, we should note another possible reason, for example, the horizontal positional error between the field treetop and the stem as mentioned before. In fact, the results in Table 5 indicate that LiDAR-detected local maxima tilted toward the valley side (i.e., southwestern) from locations of stems. LiDARderived tree heights calculated with a distance between local maximum on DSM and DTM just below the local maximum would be overestimates in forests with steep slopes (HIRATA, 2004; TAKAHASHI et al., 2005a). Moreover, the magnitude of overestimates increased with the increase of laser-sampling density (Table 6). According to Gaveau and Hill (2003), the failure of sampling treetops because of an insufficient lasersampling density is likely to occur in coniferous woodlands where crown shape is more conical than in broadleaf woodlands where crowns are more rounded. NÆSSET and ØKLAND (2002) concluded that the observed standard deviations in tree height residuals in LiDAR data for a forest

Table 7 Characteristics of detected, ambivalently detected, and undetected trees

\begin{tabular}{lccc}
\hline & Detected $^{\mathrm{a}}$ & Ambivalently detected $^{\mathrm{c}}$ & Undetected $^{\mathbf{b}}$ \\
\hline${\text { Rate }(\%)^{\mathbf{d}}}^{\mathrm{d}}$ & 54.6 & 14.6 & 30.8 \\
${\text { Crown radius }(\mathrm{m})^{\mathbf{e}}}$ & 2.2 & 1.5 & 1.2 \\
Tangent $^{\mathrm{f}}$ & -1.2 & -0.2 & 2.0 \\
Horizontal distance $(\mathrm{m})^{\mathrm{f}}$ & 2.4 & 1.9 & 1.7 \\
Vewing angle (degree) $^{\mathbf{f}}$ & -31.5 & 3.9 & 45.9 \\
\hline
\end{tabular}

${ }^{\mathrm{a}}$ Detected same trees among all datasets

${ }^{\mathbf{b}}$ Undetected same trees among all datasets

${ }^{\mathrm{c}}$ Trees which were either detected or undetected among different datasets

d Percentage of the number of detected, ambivalently detected, and undetected trees

e Mean crown radius

${ }^{\mathbf{f}}$ Tangent $(\tan \theta)$ consistes of horizontal distance and viewing angle (depression or elevation angle) from a given field treetop to the closest field treetop (see Fig. 1). Depression and elevation angle have negative and positive value, respectively. 
dominated by Norway spruce (Picea abies) could be improved by increasing laser-sampling density. Considering these reports, the phenomenon that the errors of overestimations were increasing with the increase of laser-sampling density is not surprising.

Fig. 4 indicates that the accuracy of LiDAR-derived individual-tree heights was really high for all datasets. We should note that the number of detected small trees between $10 \mathrm{~m}$ and $18 \mathrm{~m}$ height are increasing with the increase of lasersampling density, and such trees fit correctly each regression line in this figure. According to the regression analysis, the intercepts of all regression equations did not significantly differ from zero $(p>0.05)$, thus indicating that the mean error of the regression equations was not significant. Moreover, the slopes for all regression equations could be statistically regarded as one $(\phi>0.05)$, thus indicating that the error between $h_{\mathrm{L}}$ and $h_{\mathrm{f}}$ was independent of tree size. Furthermore, the difference between maximum and minimum RMSE for tree height estimates was only $0.17 \mathrm{~m}$, and the maximum RMSE was $1.02 \mathrm{~m}$ in this study site (Table 6). This accuracy was almost the same as we previously reported that we used a helicopter-borne LiDAR system in the same site for individualtree height estimation (TAKAHASH et al., 2005a). Therefore, all results of this study indicate that although greater lasersampling density data can provide information of more varying tree size, 3 or 4 points $/ \mathrm{m}^{2}$ of laser-sampling density data would provide accurate individual-tree detection of upper-storey trees and tree height estimates, given as RMSE, is approximately $1 \mathrm{~m}$ in middle-aged Japanese cedar forests in mountainous areas.

Table 8 Statistical significant difference for the average of tree heights tested by Friedman test and Scheffe procedure

\begin{tabular}{|c|c|c|c|c|}
\hline Group 1 & Group 2 & Chi-square statistic & $P$ value & \\
\hline Field tree height & $S_{1}$ & 31.8597 & 0.0000 & ** \\
\hline Field tree height & $\mathrm{S}_{2}$ & 86.5352 & 0.0000 & ** \\
\hline Field tree height & $\mathrm{S}_{3}$ & 48.3386 & 0.0000 & ** \\
\hline Field tree height & $\mathrm{D}_{12}$ & 140.3292 & 0.0000 & ** \\
\hline Field tree height & $D_{13}$ & 109.5211 & 0.0000 & ** \\
\hline Field tree height & $\mathrm{D}_{23}$ & 130.7418 & 0.0000 & ** \\
\hline Field tree height & $T_{123}$ & 210.5640 & 0.0000 & ** \\
\hline $\mathrm{S}_{1}$ & $\mathrm{~S}_{2}$ & 13.3809 & 0.0634 & \\
\hline$S_{1}$ & $\mathrm{~S}_{3}$ & 1.7113 & 0.9741 & \\
\hline$S_{1}$ & $D_{12}$ & 38.4601 & 0.0000 & ** \\
\hline$S_{1}$ & $\mathrm{D}_{13}$ & 23.2400 & 0.0015 & ** \\
\hline $\mathrm{S}_{\mathbf{1}}$ & $\mathrm{D}_{23}$ & 33.5217 & 0.0000 & ** \\
\hline$S_{1}$ & $\mathrm{~T}_{123}$ & 78.6127 & 0.0000 & ** \\
\hline $\mathrm{S}_{2}$ & $\mathrm{~S}_{3}$ & 5.5217 & 0.5966 & \\
\hline $\mathrm{S}_{2}$ & $\mathrm{D}_{12}$ & 6.4701 & 0.4861 & \\
\hline $\mathrm{S}_{2}$ & $D_{13}$ & 1.3521 & 0.9870 & \\
\hline$S_{2}$ & $\mathrm{D}_{23}$ & 4.5446 & 0.7153 & \\
\hline $\mathrm{S}_{2}$ & $T_{123}$ & 27.1273 & 0.0003 & ** \\
\hline $\mathrm{S}_{3}$ & $\mathrm{D}_{12}$ & 23.9460 & 0.0012 & ** \\
\hline $\mathrm{S}_{3}$ & $\mathrm{D}_{13}$ & 12.3386 & 0.0900 & \\
\hline $\mathrm{S}_{3}$ & $\mathrm{D}_{23}$ & 20.0851 & 0.0054 & ** \\
\hline $\mathrm{S}_{3}$ & $T_{123}$ & 57.1268 & 0.0000 & ** \\
\hline $\mathrm{D}_{12}$ & $\mathrm{D}_{13}$ & 1.9067 & 0.9648 & \\
\hline $\mathrm{D}_{12}$ & $\mathrm{D}_{23}$ & 0.1696 & 1.0000 & \\
\hline $\mathrm{D}_{12}$ & $T_{123}$ & 7.1009 & 0.4184 & \\
\hline $\mathrm{D}_{13}$ & $\mathrm{D}_{23}$ & 0.9390 & 0.9958 & \\
\hline $\mathrm{D}_{13}$ & $T_{123}$ & 16.3668 & 0.0220 & * \\
\hline $\mathrm{D}_{23}$ & $\mathrm{~T}_{123}$ & 9.4654 & 0.2209 & \\
\hline \multicolumn{5}{|c|}{${ }^{*} P<0.05 ;{ }^{* *} P<0.01$} \\
\hline \multicolumn{5}{|c|}{ a Three sets of single flight data, i.e., $\mathrm{S}_{1}, \mathrm{~S}_{2}$, and $\mathrm{S}_{3}$} \\
\hline \multicolumn{5}{|c|}{$\begin{array}{l}\text { Three sets of double-overlapping data }\left(D_{12}, D_{13} \text {, and } D_{23}\right) \text { consisted of } S_{1} \text { and } S_{2} \\
S_{1} \text { and } S_{3} \text {, and } S_{2} \text { and } S_{3} \text {, respectively. }\end{array}$} \\
\hline
\end{tabular}




\section{LITERATURE CITED}

GaveaU, D. L. A. and Hill, R. A., (2003): Quantifying canopy height underestimation by laser pulse penetration in small-footprint airborne laser scanning data. Can. J. Remote Sens. 29: 650-657

Heurich, M., SchNeIder., T. and KenNEL., E., (2003): Laser scanning for identification of forest structures in the Bavarian Forest National Park. Proceedings of ScandLaser, 2-4 September, Umeå, Sweden 97-106

HiRATA, Y., (2004): The effects of footprint size and sampling density in airborne laser scanning to extract individual-trees in mountainous terrain. Int. Arc. Photogramm. Remote Sens. and Spatial Info. Sci. 36: part8/w2

Hyyppä, J., Kelle, O., Lehikoinen, M. and Inkinen, M., (2001): A segmentation-based method to retrieve stem volume estimates from 3-D tree height models produced by laser scanners. IEEE Trans. Geosci. Remote Sens. 39: 969-975

Hollander, M. and Wolfe, D. A., (1973): Nonparametric statistical inference. New York: John Wiley \& Son. 139-146

Holmgren, J., Nilsson, M. and Olsson, H., (2003) Simulating the effects of lidar scanning angle for estimation of mean tree height and canopy closure. Can. J. Remote Sens. 29: 623-632

Kraus, K. and Pfeifer, N., (1998): Determination of terrain models in wooded areas with airborne laser scanning data. ISPRS $\mathrm{J}$. Photogramm. Remote Sens. 53: 193-203

Lovell, J. L., Jupp, D. L. B., Newnham, G. J., Coops, N. C. and Culvenor, D. S., (2005): Simulation study for finding optimal lidar acquisition parameters for forest height retrieval. For. Ecol. Man. 214: $398-412$

Magnussen, S. and Boudewyn, P., (1998): Derivations of stand heights from airborne laser scanner data with canopy-based quantile estimators. Can. J. For. Res. 28: 1016-1031

Maltamo, M., Eerikärnen, K., PitKänen, J., Hyyppä, J. and Vehmas, M., (2004): Estimation of timber volume and stem density based on scanning laser altimetry and expected tree size distribution functions. Remote Sens. Environ. 90: 319-330

NжSSET, E. and ØKLAND, T., (2002): Estimating tree height and tree crown properties using airborne scanning laser in a boreal nature reserve. Remote Sens. Environ. 79: 105-115

Nilson, M. and Holmgren, J., (2003): Prediction of forest variables using LIDAR measurements with different footprint size and measurement densities. Proceedings of ScandLaser, 2-4 September, Umeå, Sweden: 124-132

Persson, A., Holmgren, J. and Soderman, U., (2002): Detecting and measuring individual-trees using an airborne laser scanner. Photogramm. Eng. Remote Sens. 68: 925-932

Popescu, S. C., Wynne, R. H. and Nelson, R. F., (2002): Estimating plot-level tree heights with lidar: local filtering with a canopyheight based variable window size. Com. Elect. Agr. 37: 71-95

Riaño, D., Meier, E., Aligöwer, B., Chuvieco, E. and Ustin, S.L., (2003): Modeling airborne laser scanning data for the spatial generation of critical forest parameters in fire behavior modeling. Remote Sens. Environ. 86: 177-186

RichaRDS, F., (1958): A flexible growth function to empirical use. J. Experi. Bot. 10: 290-300

Takahashi, T., Yamamoto, K., Senda, Y. and Tsuzuku, M., (2005a): Estimating individual-tree heights of sugi (Cryptomeria japonica D. Don) plantations in mountainous areas using small-footprint airborne LiDAR. J. For. Res. 10: 135-142

Takahashi, T., Yamamoto, K., Senda, Y. and Tsuzuku, M., (2005b): Predicting individual stem volumes of sugi (Cryptomeria japonica D. Don) plantations in mountainous areas using small-footprint airborne LiDAR. J. For. Res. 10: 305-312

Takahashi, T., Yamamoto, K., Miyachi, Y., Senda, Y. and Tsuzuku, M., (2006): The penetration rate of laser pulses transmitted from a small-footprint airborne LiDAR: a case study in closed-canopy, middle-aged pure sugi (Cryptomeria japonica D. Don) and hinoki cypress (Chamaecyparis obtusa Sieb. et Zucc.) stands in Japan. J. For. Res. 11: 117-123.

Wulder, M., Niemann, K. O. and Goodenough, D. G., (2000): Local maximum filtering for the extraction of tree locations and basal area from high spatial resolution imagery. Remote Sens. Environ. 73: 103-114

Yu, X., Hyyprä, J., Hyyppä, H. and Maltamo, M., (2004): Effects of flight altitude on tree height estimation using airborne laser scanning. Int. Arc. Photogramm. Remote Sens. and Spatial Info. Sci. 36: part8/w2

Zimble, D. A., Evans, D. L., Carlson, G. C., Parker, R. C., Grado, S. C. and GERARD, P. D., (2003): Characterizing vertical forest structure using small-footprint airborne LiDAR. Remote Sens. Environ. 87: $171-182$

(Recceived 17 January 2007) (Accepted 28 October 2007) 